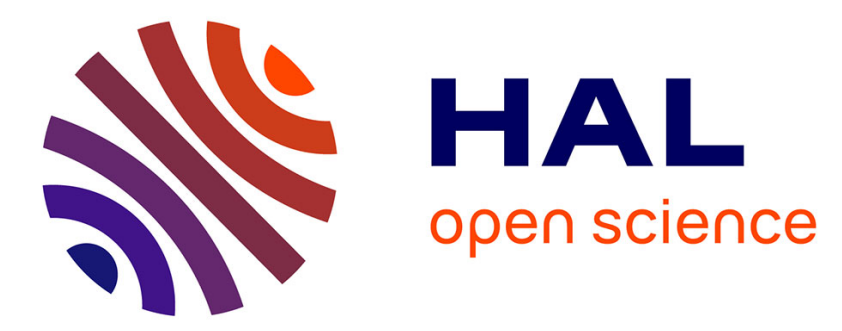

\title{
Growth arrest-specific protein 6 deficiency impairs liver tissue repair after acute toxic hepatitis in mice.
}

\author{
Fouad Lafdil, Marie-Noële Chobert, Vanessa Deveaux, Elie-Serge Zafrani,
} Philippe Mavier, Toru Nakano, Yannick Laperche, Arthur Brouillet

\section{- To cite this version:}

Fouad Lafdil, Marie-Noële Chobert, Vanessa Deveaux, Elie-Serge Zafrani, Philippe Mavier, et al.. Growth arrest-specific protein 6 deficiency impairs liver tissue repair after acute toxic hepatitis in mice.: Gas6 deficiency impairs hepatic wound healing. Journal of Hepatology, 2009, 51 (1), pp.55-66. 10.1016/j.jhep.2009.02.030 . inserm-00405375

HAL Id: inserm-00405375 https://www.hal.inserm.fr/inserm-00405375

Submitted on 20 Jul 2009

HAL is a multi-disciplinary open access archive for the deposit and dissemination of scientific research documents, whether they are published or not. The documents may come from teaching and research institutions in France or abroad, or from public or private research centers.
L'archive ouverte pluridisciplinaire HAL, est destinée au dépôt et à la diffusion de documents scientifiques de niveau recherche, publiés ou non, émanant des établissements d'enseignement et de recherche français ou étrangers, des laboratoires publics ou privés. 
GROWTH ARREST-SPECIFIC PROTEIN 6 DEFICIENCY IMPAIRS LIVER TISSUE REPAIR AFTER ACUTE TOXIC HEPATITIS IN MICE

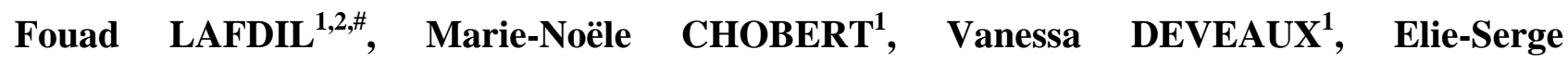
ZAFRANI $^{1,2,3}$, Philippe MAVIER $^{1,2}$, Toru NAKANO ${ }^{4}$, Yannick LAPERCHE ${ }^{1,2}$ and Arthur BROUILLET ${ }^{1,2}$.

${ }^{1}$ INSERM, U955, Créteil, F-94010

${ }^{2}$ Université Paris 12 Val-de-Marne, Créteil, F-94010

${ }^{3}$ AP-HP, Groupe Henri Mondor-Albert Chenevier, Département de Pathologie, Créteil, F-94010

${ }^{4}$ Shionogi Research Laboratories, Shionogi \& Co, Ltd., Osaka, Japan

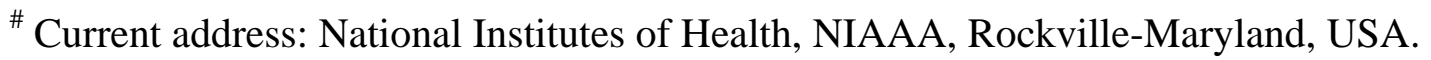

Short title : Gas6 deficiency impairs hepatic wound healing

Corresponding author: Yannick LAPERCHE, INSERM, U955 Institut Mondor de Recherche Biomédicale, Créteil, F-94010

Tel : +33 (0)1 49813544

e-mail : yannick.laperche@inserm.fr

Electronic Word Count : 4940

7 Figures and 1 Table 


\begin{abstract}
Background \& Aims : Resident macrophages and myofibroblasts derived from hepatic stellate cells play a key role in liver wound healing. We previously reported that these sinusoidal cells secrete the growth arrest-specific protein 6 (Gas6) and express Axl, one of its receptors. We address now the role of Gas6 in healing process during acute liver injury. Methods : Toxic hepatitis was induced by a single carbon tetrachloride injection in Gas6 deficient $\left(\mathrm{Gas6}^{-/}\right)$mice and liver recovery was compared with wild type animals. Results : Gas6 deficiency did not cause any change in $\mathrm{CCl}_{4^{-}}$ induced liver damage. At 72 hour, an efficient tissue repair was observed in wild type animals whereas in $\mathrm{Gas6}^{-/-}$mice, we noticed a defective wound healing accounted by reduced Kupffer cell activation revealed by a decrease in the induction of CD14, TNF- $\alpha$, IL6 and MCP-1. Gas6deficiency, by limiting cytokine/chemokine release, prevents hepatocyte proliferation, recruitment of circulating monocytes and accumulation of myofibroblasts in healing areas. We also report a direct chemotactic effect of Gas6 on circulating monocytes which might explain defective macrophage infiltration in liver necrotic areas of $\mathrm{Gas}^{-/-}$mice. Interestingly in $\mathrm{Gas}^{-/-}$mice, we observed a high and constitutive expression of Axl and an induction of the suppressor of cytokine signaling SOCS1 after $\mathrm{CCl}_{4}$ treatment. Conclusions : The lower level of cytokines/chemokines in $\mathrm{Gas6}^{-/-}$mice after $\mathrm{CCl}_{4}$ injury, is the consequence of an inhibitory signal arising from Axl receptor overexpression, leading to delayed liver repair in deficient mice.
\end{abstract}

\title{
Electronic Word Count : 240
}

Keywords: Liver repair, Inflammation, Kupffer cells, Growth arrest-specific protein 6, Axl. 


\section{Introduction}

In response to acute injury, liver elicits a wound healing process characterized by proliferation of unaltered hepatocytes, clearance of cell debris and matrix remodeling leading to recovery of a normal hepatic structure. In various forms of hepatitis, Kupffer cells, the liver resident macrophages, are involved at one and the same time in hepatocyte death and initiation of wound healing [1]. In addition to their phagocytic properties, Kupffer cells respond immediately to the injury by releasing proinflammatory mediators such as tumor necrosis factor alpha (TNF- $\alpha$ ) and interleukin 6 (IL6) that trigger hepatocyte proliferation [2] and monocyte chemoattractant protein-1 (MCP-1) which drives monocyte/macrophage recruitment to the lesion [3]. Evidence for a key role of liver macrophages in hepatic injury and repair has been provided by alteration in hepatic cytokine expression and delayed liver regeneration in animals depleted in Kupffer cells [4, 5]. Resident and recruited monocytes/macrophages are also involved in activation of hepatic stellate cells (HSC) into myofibroblasts (HSC/MFB) [6, 7], which secrete proteases and matrix proteins necessary to tissue remodeling. The central role of HSC/MFB in liver repair was clearly shown in mice where reduced HSC-myofibroblastic transformation was associated with a defective liver regeneration $[8,9]$.

The protein product of the growth arrest-specific gene 6 (Gas6) and its tyrosine kinase Tyro-3, Axl and Mer receptors (TAM receptors) have been implicated in growth and survival processes during development and tissue repair. Gas6/Axl signaling induces accumulation of mesangial cells in kidney fibrosis [10] and vascular smooth muscle cells in response to vascular injury [11] as well as proliferation of cardiac fibroblasts [12]. Gas6 is known as a chemo-attractant protein for vascular smooth muscle cells [13], interfering with cell adhesion and stabilizing platelet aggregation [14]. A recent study also demonstrates that Gas6 plays a pivotal role in leukocyte infiltration into inflamed tissue [15]. In normal liver, we previously showed that Gas6 is expressed by resident macrophages and, after hepatic injury, in HSC along with their transformation into HSC/MFB [16]. In addition, Axl, the receptor with the highest affinity for Gas6, is expressed in liver macrophages and 
HSC/MFB and Gas6 protects HSC/MFB from apoptosis in vitro [16]. These results suggest that Gas6/Axl signaling might be involved in the wound healing response to liver injury.

In order to directly address the role of Gas6 produced by macrophages and HSC/MFB in liver repair, we studied the healing process in Gas6 deficient $\left(\mathrm{Gas6}^{-/}\right)$mice after a single carbon tetrachloride $\left(\mathrm{CCl}_{4}\right)$-injection, a well-known model of acute hepatitis [8]. We report an impairment of liver repair in $\mathrm{Gas6}^{--}$mice, which was associated with delayed hepatocyte proliferation related to a default in Kupffer cell activation and reduced macrophage infiltration and HSC myofibroblastic transformation in necrotic areas. It is noteworthy that in these deficient mice, there is a high and constitutive expression of Axl leading to induction of the suppressor of cytokine signaling SOCS1 synthesis after $\mathrm{CCl}_{4}$ injection [17]. These results might account for lower release of cytokine/chemokine in response to the injury and explain the delayed liver repair in Gas6 $6^{-/}$mice. 


\section{Materials and Methods}

Animal model of liver injury : Studies were performed on 8-12 week old male Gas6 ${ }^{-/-}$mice bred for 18 generations in the C57BL/6 genetic background [18] and wild type (WT) C57BL/6 mice (Janvier Animal Center, France). Mice treated with a single intraperitoneal injection of $\mathrm{CCl}_{4}$ (4 $\mathrm{ml} / \mathrm{kg}$ body weight) diluted in olive oil (1/1) and control mice injected with vehicle only, were killed at different time points (from 3 hours to 7 days) after the injection. Four of 66 mice from Gas6 $^{-/-}$group died on day 2 after $\mathrm{CCl}_{4}$ injection, whereas all WT mice (78 animals) survived to the entire experiments. Livers were collected and treated as previously described [19]. Serum alanine aminotransferase (ALT) and aspartate aminotransferase (AST) activities were measured using an Advia 1650 automate (Bayer Diasys). All animal manipulations were performed according to the recommendations of the French ethical committee and under the supervision of authorized investigators.

Histological and immunohistochemical analysis : Liver injury was assessed on $4 \mu \mathrm{m}$-thick paraffin-embedded liver sections stained with haematoxylin and eosin (H\&E). Necrosis was graded on a 4-point scale $(0,1,2$ and 3$)$ in 20 random fields at $100 \mathrm{X}$ magnification : absence of necrotic area corresponded to index 0 and index 3 corresponded to the maximal value for necrosis observed in a field (up to $50 \%$ of the field area). Immunohistochemistry was carried out on paraffinembedded or $5 \mu$ m-thick frozen sections as previously described [19]. Primary antibodies were mouse monoclonal anti-proliferating cell nuclear antigen (PCNA) (Santa Cruz), mouse monoclonal anti- $\alpha$-smooth muscle actin ( $\alpha$-SMA) (Sigma), rat monoclonal directed against mouse F4/80 and CD68 (Serotec). For immunodetection with mouse monoclonal primary antibodies (PCNA, $\alpha$ SMA), mouse IgG proteins were blocked using the MOM kit (Vector) and endogenous peroxidase activity by $3 \% \mathrm{H}_{2} \mathrm{O}_{2}$ in $1.5 \%$ horse serum in PBS; sections were revealed by the Vectastain system (Vector) using DAB (Pierce) as peroxidase substrate [19]. For F4/80 staining, sections were revealed by the streptavidin-alkaline phosphatase conjugate (GE Healthcare) and the FastRed 
substrate system (Dako). Fluorescent labeling of CD68 was achieved using secondary FITC coupled anti-rat IgG STAR 80F (Serotec).

Protein analysis : Fifty $\mu \mathrm{g}$ of protein from snap frozen liver were used for western blotting as previously described [16] using antibodies against PCNA (Sigma), phospho-Axl-Y779 (R\&D systems), Axl (Santa Cruz) and phospho-NFkBp65-Ser536 (Cell Signaling). Anti- $\beta$-actin clone AC15 antibody (Sigma) was used to correct for unequal loadings. IL6 concentration was determined using a commercial ELISA kit (R\&D systems) in plasma samples and in $250 \mu \mathrm{g}$ of protein from snap frozen liver.

RNA analysis : Total RNA ( $2 \mu \mathrm{g})$ isolated from liver using the RNeasy mini kit (Qiagen) were reverse-transcribed from random hexamers using a first-stand synthesis kit (Fermentas, Life Sciences) and specific cDNA amplifications were performed as previously described [19] using primers listed in Table 1. Ratio of target mRNA relative to ribosomal 18S RNA was expressed as fold induction over values obtained from WT animals injected with vehicle.

Cell migration assays : Human peripheral blood mononuclear cells (PBMC) were isolated on Ficoll-Paque PLUS (Amersham Biosciences) density gradient. Monocytes were purified from PBMC by an adhesion step [3]. Purity, estimated by May Grünwald Giemsa staining of cytospined cells, ranged from 80 to 90\%. Migration assays were performed in Falcon inserts (3 $\mu$ m-pore diameter, BD Biosciences). Purified monocytes (5 $10^{5}$ cells) were transferred into the upper chamber in Ham's F12-medium and mouse recombinant Gas6 $(1 \mu \mathrm{g} / \mathrm{ml})$ or human recombinant MCP-1 (20 ng/ml) (R\&D systems) diluted in $10 \mu \mathrm{g} / \mathrm{ml}$ BSA was added in the lower chamber. The same concentration of BSA was added in the upper chamber. After 20 hours of incubation at $37^{\circ} \mathrm{C}$ in an atmosphere of $5 \% \mathrm{CO}_{2}$, migrated monocytes were counted in the lower compartment. Chemotaxis toward Ham's F12 medium containing BSA only was considered as non specific effect. 
Statistical analysis : All data are expressed as mean \pm SEM. Statistical analysis were performed using the non-parametric Mann-Whitney U-test for significance using PRISM (GraphPad). A Pvalue of less than or equal to 0.05 indicated a significant difference between groups.

\section{Results}

\section{Liver healing is delayed in Gas6-deficient mice.}

$\mathrm{CCl}_{4}$ treatment induced hepatocellular necrosis revealed by an increase of serum ALT/AST activities, which reached their maximal values between 24 and 48 hours in WT and Gas6 $6^{-/-}$mice, and decreased thereafter to normal values at 96 hour (Figure 1A, B). Serum transaminase activities in both groups were not significantly different at each time point, indicating that Gas6 deficiency did not modify the extent of $\mathrm{CCl}_{4}$-induced liver necrosis.

Analysis of liver sections from $\mathrm{CCl}_{4}$-treated mice revealed a maximal centrilobular necrosis at 48 hour which represented up to $50 \%$ of the surface of the sections in WT and Gas6 ${ }^{-/}$mice (Figure 2A). At 72 hour, necrotic areas were reduced by half in $\mathrm{CCl}_{4}$-treated WT mice but remained unchanged in $\mathrm{Gas6}^{-/-}$mice. (Figure 2A, B). A tissue repair was detected only one day later in deficient mice, at 96 hour, and was limited as compared to WT animals. Seven days after $\mathrm{CCl}_{4}$ injection, the liver recovered a normal structure in both groups (data not shown). The significant delay in liver repair observed in deficient mice, reveals that Gas6 is involved in liver wound healing after an acute toxic hepatitis.

\section{Gas6 deficiency delays hepatocyte proliferation in response to $\mathbf{C C l}_{4}$-induced injury.}

In WT mice, $\mathrm{CCl}_{4}$ injury induced a significant increase in liver PCNA amount detected by western blotting 48 hours after injection (Figure 3A, B), in accordance with previous reports [20]. Immunohistochemical detection of PCNA (Figure 3C) revealed hepatocytes with stained nuclei outside necrotic areas 48 and 72 hours after $\mathrm{CCl}_{4}$ injury in agreement with western blot analysis. In 
$\mathrm{Gas6}^{-{ }^{--}}$mice, both induction in liver PCNA level and PCNA labeling of hepatocyte nuclei were only detected at 72 hour (Figure 3A, C). Therefore defective wound healing in $\mathrm{Gas6}^{-/-}$mice was associated with one-day delay in the hepatocyte proliferative response to acute liver injury.

\section{Gas6 deficiency reduces Kupffer cell activation and cytokine synthesis in $\mathrm{CCl}_{4}$-induced hepatitis.}

Liver regeneration requires priming of quiescent hepatocytes which is achieved by cytokines, including IL6 and TNF- $\alpha$ released upon activation of Kupffer cells [2]. After i.p. $\mathrm{CCl}_{4}$ administration, plasma IL6 level rapidly increased as previously shown [21] but values in WT and $\mathrm{Gas6}^{-/-}$mice were not significantly different at 24 and 48 hours $(237 \pm 92$ versus $271 \pm 132 \mathrm{pg} / \mathrm{ml}$ respectively). However, we revealed a significantly reduced IL6 protein in liver of deficient mice (Figure 3D). Analysis of hepatic expression of IL6 and TNF- $\alpha$ at the mRNA level (Figure 4A, B), showed a gradual increase of both cytokine expression from 16 to 48 hour after $\mathrm{CCl}_{4}$ injection in WT mice (up to 16 fold induction over basal level). As expected, the increase in cytokine synthesis precedes the hepatocyte proliferative response. By contrast in Gas6-deficient mice, IL6 mRNA induction was largely blunted following $\mathrm{CCl}_{4}$ exposure and TNF- $\alpha$ mRNA induction was delayed, starting from 24 hour to reach its maximal value at 72 hour. The lower level of these two cytokines in Gas6-deficient mice could reflect lower Kupffer cell activation. We explore this hypothesis by analyzing expression of CD14, a lipopolysaccharide co-receptor [22], which is up-regulated during the activation of Kupffer cell in response to $\mathrm{CCl}_{4}$-induced injury [23]. We observed a strong induction in hepatic CD14 mRNA level 16 hours after $\mathrm{CCl}_{4}$ exposure in WT mice which decreased thereafter (Figure 4C). Such an induction was largely reduced in Gas6 ${ }^{-/-}$mice. We also analyzed the expression of monocyte chemoattractant protein 1 (MCP-1) (Figure 4D), an essential chemokine secreted by activated Kupffer cells [24]. In WT mice, hepatic MCP-1 mRNA level gradually increased from 16 hour, reached its maximal value (120 times over the basal level) 48 hours after $\mathrm{CCl}_{4}$ injection and decreased thereafter. In Gas6-deficient mice, MCP-1 mRNA induction was 
delayed and strongly blunted since its maximal value at 48 hour represented only $30 \%$ of the level in treated-WT animals. Reduced hepatic expression of CD14, MCP-1, TNF $\alpha$, and IL6 is consistent with defective Kupffer cell activation which could explain delayed liver repair in Gas6 $6^{-/-}$mice.

\section{Monocyte/macrophage infiltration in liver necrotic areas is reduced in Gas6 $^{-/-}$mice.}

To explore the consequence of reduced Kupffer cell activation and MCP-1 expression in $\mathrm{CCl}_{4}$ treated Gas6 ${ }^{-/}$mice, liver sections were first examined for the presence of monocytes/macrophages by F4/80 immunostaining [25]. Forty-eight hours after injury, F4/80 staining revealed uniformly dispersed macrophages in the unaltered parts of the lobule as well as in necrotic areas in WT and Gas6-deficient mice (Figure 5A), a distribution which was not different from Kupffer cell labeling in control mice (data not shown). At 72 hour, the massive accumulation of F4/80-positive cells detected in the centrilobular areas in WT mice was strongly decreased in Gas6 ${ }^{-/-}$mice. This marked reduction of monocyte/macrophage infiltration in deficient mice was confirmed by the CD68 labeling, another classical macrophage-specific marker (Figure 5B) and was corroborated by real time RT-PCR analysis indicating reduced CD68 mRNA levels in liver of Gas6 ${ }^{-/-}$mice (Figure 5C). It is noteworthy that the early induction of CD14 mRNA levels, peaking at 16 and 24 hours in $\mathrm{CCl}_{4}$ treated mice (Figure 4C), preceded accumulation of macrophages in injured liver confirming thus that the precocious induction of liver CD14 synthesis reflected an activation of resident macrophages, largely prevented in deficient mice.

Gas6/Axl signaling was reported to induce chemotaxis of rat vascular smooth muscle cells [13]. Since blood monocytes express the Gas6-receptors Axl and Mer [26], we investigated whether Gas6 signaling could promote blood monocyte recruitment by a direct chemotactic effect. Migration assays conducted in Boyden's chambers showed that recombinant Gas6 induced migration of purified human peripheral blood monocytes, which represented $70 \%$ of the migration obtained with recombinant MCP-1 (Figure 5D), the most powerful and specific chemotactic factor for monocytes/macrophages. Therefore, absence of Gas6 associated to reduced MCP-1 expression 
might explain defective macrophage infiltration and delayed wound healing in $\mathrm{CCl}_{4}$-treated $\mathrm{Gas}^{-/-}$ mice.

\section{Gas6 deficiency reduces myofibroblastic activation of $\mathrm{HSC}$ in $\mathrm{CCl}_{4}$-induced hepatitis.}

Resident and recruited macrophages are the main sources of TGF- $\beta$, an activator of quiescent HSC into myofibroblasts (HSC/MFB) [6]. The proliferative $\alpha$-SMA positive HSC/MFB transiently accumulate in healing areas and secrete cytokines, proteases and matrix proteins mandatory to recover of a normal liver architecture [27]. Real time PCR analysis revealed an increase of hepatic TGF- $\beta$ mRNA expression 24 hour after $\mathrm{CCl}_{4}$ injection in WT mice (Figure 6A), peaking to 4-fold the basal level at 72 hour and decreasing thereafter. This synthesis was not observed in Gas6 $6^{-/-}$mice up to 72 hour and, at 96 hour, the amount of TGF- $\beta$ mRNA was greater than that observed in WT mice, in agreement with the delayed repair in deficient mice. Real time PCR analysis revealed a 9fold up-regulation of $\alpha$-SMA mRNA 24 hours after $\mathrm{CCl}_{4}$ exposure in WT mice (Figure 6B), peaking to 100 -fold at 48 hour and decreasing thereafter. In Gas6 $6^{-/}$mice, no change in $\alpha$-SMA mRNA level was observed at 24 hour and the induction over basal level at 48 hour was strongly reduced as compared to WT animals. Immunohistochemical staining of $\alpha$-SMA in liver sections from $\mathrm{CCl}_{4}$-treated mice (Figure 6C) did not reveal activated HSC/MFB in WT and Gas6 ${ }^{-/-}$mice 48 hours after $\mathrm{CCl}_{4}$ treatment. At 72 hour, a strong $\alpha$-SMA staining was detected in healing areas of WT animals which decreased at 92 hour, in accordance with previous studies [8], whereas a faint $\alpha$ SMA labeling was observed in necrotic areas of deficient mice. Desmin labeling, a hallmark of quiescent and activated HSC, showed an accumulation of positive cells in liver centrilobular areas that did not differ between WT and $\mathrm{Gas6}^{-/-}$mice 72 hours after $\mathrm{CCl}_{4}$ injection (Figure 6D).

We conclude that the lower number of $\alpha$-SMA-positive HSC/MFB in Gas6 ${ }^{-/-}$mice cannot be explained by a reduced number of desmin-positive HSC but is rather due to a decreased myofibroblastic transformation of these cells. Defective myofibroblastic activation of HSC can be 
accounted by inhibition of TGF- $\beta$ synthesis related to impaired activation of resident macrophages and subsequent defect in monocyte recruitment in $\mathrm{Gas6}^{-/-}$mice.

\section{Gas6/Axl interaction and signal transduction}

Axl phosphorylation was detected by western blotting from 3 hour after $\mathrm{CCl}_{4}$ injection and decreased thereafter (Figure 7A). Nevertheless, this phosphorylation was not different between WT and $\mathrm{Gas6}^{-/}$mice. Similar findings were obtained when we analyzed phosphorylation of NFkB (Figure 7B) and STAT3 (data not shown), two downstream mediators of Gas6/Axl pathway [28]. All these data demonstrated that Gas6 deficiency did not impair the activation of this receptor in liver. However and unexpectedly, we found that total Axl protein level was constitutively overexpressed in $\mathrm{Gas6}^{-/-}$mice (Figure 7C, D). An important anti-inflammatory function of Axl has been recently elucidated which involves the induction of the inhibitory proteins SOCS [17]. Accordingly, the amount of hepatic SOCS1 expression quantified by real time PCR analysis, was significantly increased in $\mathrm{Gas6}^{-/-}$mice as compared to WT animals, 16 hours after $\mathrm{CCl}_{4}$ injection (Figure 7E). In basal condition, a high Axl level was not sufficient to induce SOCS1 mRNA, indicating that this upregulation occurs only in the inflammatory environment induced by $\mathrm{CCl}_{4}$. During this early phase of injury, Axl mRNA expression was not significantly different in WT and Gas6 $^{-/-}$mice (data not shown), suggesting that a transcriptional regulation does not explain the difference in Axl protein levels observed between the two genotypes. 


\section{Discussion}

In the liver, Kupffer cells play a central role in wound healing. Unlike monocyte, these resident macrophages have low baseline expression of CD14, which is up-regulated upon their activation by multiple stimuli [22], including $\mathrm{CCl}_{4}$ [23]. These cells respond immediately to the injury by releasing mediators which orchestrate the inflammatory response and the activation of HSC leading to the reparative process [1]. To investigate the functional importance of Gas6/Axl pathway in liver regeneration, we induced acute injury in Gas6-deficient mice by a single $\mathrm{CCl}_{4}$ injection and we analyzed the impact of this deficiency on liver necrosis and healing.

As previously observed [29-31], $\mathrm{CCl}_{4}$ induced a centrilobular necrosis which was maximal at 48 hour and an efficient tissue repair observed at 72 hour in WT mice. Activation of Kupffer cells was revealed by a rapid and marked up-regulation of hepatic CD14 expression starting 16 hours after $\mathrm{CCl}_{4}$ injection and a strong induction in synthesis of IL6, TNF- $\alpha$ and MCP-1 cytokines released from activated Kupffer cells. This activation in response to $\mathrm{CCl}_{4}$ injury appears as a primary event in liver repair that triggers hepatocyte proliferation at 48 hour, as well as recruitment of circulating monocytes and activation of HSC into myofibroblasts in necrotic areas 72 hours after injection.

Gas6 deficiency did not cause any significant change in $\mathrm{CCl}_{4}$-induced liver damage, as shown by similar serum ALT and AST activities and similar extent of centrilobular necrotic areas in liver of both WT and deficient mice 2 days after the injury. However, repair of liver necrotic areas was clearly delayed in Gas6-deficient animals as compared to WT mice. Inhibition of $\mathrm{CCl}_{4}$-induced CD14 synthesis in Gas6 ${ }^{-/-}$mice demonstrated a defective Kupffer cell activation also revealed by a decrease in liver TNF- $\alpha$, IL6, MCP-1 and TGF- $\beta$ synthesis. Impaired IL6 and TNF secretion can account for the inhibition of hepatocyte proliferation. Decreased macrophage infiltration observed in Gas6-deficient mice at 72 hour can be explained by inhibition of MCP-1 synthesis as well as by the absence of Gas6 chemotatic effect on Axl-positive circulating monocytes. Moreover, a recent report demonstrated that Gas6 is involved in leukocyte extravasation [15], notably by up-regulating vascular cell adhesion molecule-1 (VCAM-1). Accordingly, we observed an induction of VCAM-1 
expression in $\mathrm{CCl}_{4}$-treated WT mice, which was largely prevented in $\mathrm{Gas6}^{-/-}$mice (data not shown). Finally, defective Kupffer cell activation and monocyte recruitment in deficient mice, leading to decreased TGF- $\beta$ synthesis, might be responsible for impairment of HSC myofibroblastic transformation and, consequently, for defective wound healing process.

Mechanism by which Gas6 controls activation of Kupffer cells and the subsequent cytokine synthesis remains unclear. We observed a comparable phosphorylation of Axl and its downstream mediators NFkB or STAT3 in both genotypes, indicating that Gas6 deficiency did not alter Axl signaling. In addition in WT mice, Gas6 mRNA was not significantly induced after $\mathrm{CCl}_{4}$ injection (data not shown). Altogether, these data suggest that Axl signaling in deficient mice could be due to the binding of protein S, another Axl ligand, which displays a lower affinity for Axl, but which is highly expressed in the liver. Reduced cytokine synthesis in $\mathrm{Gas}^{-/-}$mice might also be related to defective clearance of apoptotic cells. Indeed, Gas6 and protein S are involved in engulfment of apoptotic bodies by Kupffer cells [32] promoting their activation and the subsequent TNF- $\alpha$ synthesis [33].

More interestingly, we observed higher total Axl protein levels in $\mathrm{Gas6}^{-/-}$mice than in WT animals and increasing evidences demonstrate that Axl could induce biological effects via direct interactions with cytokine receptors [17, 34, 35]. Several studies also report inhibition of TNF $\alpha$ and IL6 expression induced by TAM receptors [36, 37] and this anti-inflammatory response is clearly illustrated by hypersensitivity of mutant mice lacking all three receptors to LPS-induced endotoxic shock and their susceptibility to autoimmune diseases attributed to hyperactivation of macrophages [38]. This TAM-mediated anti-inflammatory effect is due to an upregulation of Axl which interacts with the interferon receptor; then this complex induces the suppressor of cytokine signaling SOCS proteins which limits inflammation [17]. In Gas6 ${ }^{-/-}$mice, the constitutive high level of Axl, might hold down the inflammatory response after $\mathrm{CCl}_{4}$ injection, an hypothesis supported by induction of SOCS1 mRNA in those deficient mice. 
In conclusion, we uncovered that Axl receptor is under the negative control of Gas6 and we propose an explanation for reduced inflammation and delayed wound healing process in Gas6 $6^{-/-}$mice. This mechanism also accounts for opposite effects on the inflammatory response observed in Gas6 and TAM receptor knock-out mice. This study highlights the role of Gas6/Axl signaling in the fine tuning of liver inflammation required for normal wound healing.

\section{Acknowledgments}

The authors thank B. Chazaud and F. Poron for fruitful discussion and M. Bouaziz for mouse breeding and nursing. This work was supported by INSERM, University Paris 12 and Agence Nationale pour la Recherche (ANR-06-Physio-022-2). 


\section{References}

1. Bilzer M, Roggel F, Gerbes AL. Role of Kupffer cells in host defense and liver disease. Liver Int 2006;26:1175-1186.

2. Taub R. Liver regeneration: from myth to mechanism. Nat Rev Mol Cell Biol 2004;5:836847.

3. Fantuzzi L, Borghi P, Ciolli V, Pavlakis G, Belardelli F, Gessani S. Loss of CCR2 expression and functional response to monocyte chemotactic protein (MCP-1) during the differentiation of human monocytes: role of secreted MCP-1 in the regulation of the chemotactic response. Blood 1999;94:875-883.

4. Rivera CA, Bradford BU, Hunt KJ, Adachi Y, Schrum LW, Koop DR, et al. Attenuation of CCl(4)-induced hepatic fibrosis by $\mathrm{GdCl}(3)$ treatment or dietary glycine. Am J Physiol Gastrointest Liver Physiol 2001;281:G200-207.

5. Sturm E, Havinga R, Baller JF, Wolters H, van Rooijen N, Kamps JA, et al. Kupffer cell depletion with liposomal clodronate prevents suppression of Ntcp expression in endotoxin-treated rats. J Hepatol 2005;42:102-109.

6. Imamura M, Ogawa T, Sasaguri Y, Chayama K, Ueno H. Suppression of macrophage infiltration inhibits activation of hepatic stellate cells and liver fibrogenesis in rats. Gastroenterology 2005;128:138-146.

7. Duffield JS, Forbes SJ, Constandinou CM, Clay S, Partolina M, Vuthoori S, et al. Selective depletion of macrophages reveals distinct, opposing roles during liver injury and repair. J Clin Invest 2005;115:56-65.

8. Kalinichenko VV, Bhattacharyya D, Zhou Y, Gusarova GA, Kim W, Shin B, et al. Foxf1 +/mice exhibit defective stellate cell activation and abnormal liver regeneration following CCl4 injury. Hepatology 2003;37:107-117.

9. Passino MA, Adams RA, Sikorski SL, Akassoglou K. Regulation of hepatic stellate cell diffrentiation by the neurotrophin receptor $p 75^{\mathrm{NTR}}$. Science 2007;315:1853-1856. 
10. Yanagita M, Arai H, Ishii K, Nakano T, Ohashi K, Mizuno K, et al. Gas6 regulates mesangial cell proliferation through Axl in experimental glomerulonephritis. Am J Pathol 2001;158:1423-1432.

11. Melaragno MG, Wuthrich DA, Poppa V, Gill D, Lindner V, Berk BC, et al. Increased expression of Axl tyrosine kinase after vascular injury and regulation by G protein-coupled receptor agonists in rats. Circ Res 1998;83:697-704.

12. Stenhoff J, Dahlback B, Hafizi S. Vitamin K-dependent Gas6 activates ERK kinase and stimulates growth of cardiac fibroblasts. Biochem Biophys Res Commun 2004;319:871-878.

13. Fridell YW, Villa J, Jr., Attar EC, Liu ET. GAS6 induces Axl-mediated chemotaxis of vascular smooth muscle cells. The Journal of biological chemistry 1998;273:7123-7126.

14. Angelillo-Scherrer A, de Frutos P, Aparicio C, Melis E, Savi P, Lupu F, et al. Deficiency or inhibition of Gas6 causes platelet dysfunction and protects mice against thrombosis. Nat Med 2001;7:215-221.

15. Tjwa M, Bellido-Martin L, Lin Y, Lutgens E, Plaisance S, Bono F, et al. Gas6 promotes inflammation by enhancing interactions between endothelial cells, platelets, and leukocytes. Blood 2008;111:4096-4105.

16. Lafdil F, Chobert MN, Couchie D, Brouillet A, Zafrani ES, Mavier P, et al. Induction of Gas6 protein in CCL4-induced rat liver injury and anti-apoptotic effect on hepatic stellate cells. Hepatology 2006;44:228-239.

17. Rothlin CV, Ghosh S, Zuniga EI, Oldstone MB, Lemke G. TAM receptors are pleiotropic inhibitors of the innate immune response. Cell 2007;131:1124-1136.

18. Yanagita M, Ishimoto Y, Arai H, Nagai K, Ito T, Nakano T, et al. Essential role of Gas6 for glomerular injury in nephrotoxic nephritis. J Clin Invest 2002;110:239-246.

19. Couchie D, Lafdil F, Martin N, Laperche Y, Zafrani ES, Mavier P. Expression and role of growth arrest-pecific gene 6 protein and of its receptor axl in hepatic regeneration from oval cells. Gastroenterology 2005;129:1633-1642. 
20. Yu C, Wang F, Jin C, Huang X, Miller DL, Basilico C, et al. Role of fibroblast growth factor type 1 and 2 in carbon tetrachloride-induced hepatic injury and fibrogenesis. Am J Pathol 2003;163:1653-1662.

21. Zuinen R, Yamaji K, Aoki M, Chikuma T, Hojo H. Early induced, high-level interleukin-6 expression in the rat peritoneal cavity into which a hepatotoxicant carbon tetrachloride was administered. Toxicology letters 2007;170:42-48.

22. Su GL, Goyert SM, Fan MH, Aminlari A, Gong KQ, Klein RD, et al. Activation of human and mouse Kupffer cells by lipopolysaccharide is mediated by CD14. Am J Physiol Gastrointest Liver Physiol 2002;283:G640-645.

23. Qiu DK, Hua J, Li JQ, Li EL. CD14 expression on Kupffer cells during the course of carbon tetrachloride-mediated liver injury. Chin J Dig Dis 2005;6:137-141.

24. Matsukawa A, Hogaboam CM, Lukacs NW, Lincoln PM, Strieter RM, Kunkel SL. Endogenous monocyte chemoattractant protein-1 (MCP-1) protects mice in a model of acute septic peritonitis: cross-talk between MCP-1 and leukotriene B4. J Immunol 1999;163:6148-6154.

25. Leenen PJ, de Bruijn MF, Voerman JS, Campbell PA, van Ewijk W. Markers of mouse macrophage development detected by monoclonal antibodies. J Immunol Methods 1994;174:5-19.

26. Lemke G, Lu Q. Macrophage regulation by Tyro 3 family receptors. Curr Opin Immunol 2003;15:31-36.

27. Friedman SL. Molecular regulation of hepatic fibrosis, an integrated cellular response to tissue injury. The Journal of biological chemistry 2000;275:2247-2250.

28. Hafizi S, Dahlback B. Gas6 and protein S. Vitamin K-dependent ligands for the Axl receptor tyrosine kinase subfamily. FEBS J 2006;273:5231-5244.

29. Lee JI, Lee KS, Paik YH, Nyun Park Y, Han KH, Chon CY, et al. Apoptosis of hepatic stellate cells in carbon tetrachloride induced acute liver injury of the rat: analysis of isolated hepatic stellate cells. J Hepatol 2003;39:960-966.

30. Shi J, Aisaki K, Ikawa Y, Wake K. Evidence of hepatocyte apoptosis in rat liver after the administration of carbon tetrachloride. Am J Pathol 1998;153:515-525. 
31. Yamada Y, Fausto N. Deficient liver regeneration after carbon tetrachloride injury in mice lacking type 1 but not type 2 tumor necrosis factor receptor. Am J Pathol 1998;152:1577-1589.

32. Hall MO, Obin MS, Heeb MJ, Burgess BL, Abrams TA. Both protein S and Gas6 stimulate outer segment phagocytosis by cultured rat retinal pigment epithelial cells. Exp Eye Res 2005.

33. Canbay A, Feldstein AE, Higuchi H, Werneburg N, Grambihler A, Bronk SF, et al. Kupffer cell engulfment of apoptotic bodies stimulates death ligand and cytokine expression. Hepatology 2003;38:1188-1198.

34. Budagian V, Bulanova E, Orinska Z, Thon L, Mamat U, Bellosta P, et al. A promiscuous liaison between IL-15 receptor and Axl receptor tyrosine kinase in cell death control. The EMBO journal 2005;24:4260-4270.

35. Gallicchio M, Mitola S, Valdembri D, Fantozzi R, Varnum B, Avanzi GC, et al. Inhibition of vascular endothelial growth factor receptor 2-mediated endothelial cell activation by Axl tyrosine kinase receptor. Blood 2005;105:1970-1976.

36. Camenisch TD, Koller BH, Earp HS, Matsushima GK. A novel receptor tyrosine kinase, Mer, inhibits TNF-alpha production and lipopolysaccharide-induced endotoxic shock. J Immunol 1999;162:3498-3503.

37. Tibrewal N, Wu Y, D'Mello V, Akakura R, George TC, Varnum B, et al. Autophosphorylation docking site Tyr-867 in Mer receptor tyrosine kinase allows for dissociation of multiple signaling pathways for phagocytosis of apoptotic cells and down-modulation of lipopolysaccharide-inducible NF-kappaB transcriptional activation. The Journal of biological chemistry 2008;283:3618-3627.

38. Lu Q, Lemke G. Homeostatic regulation of the immune system by receptor tyrosine kinases of the Tyro 3 family. Science 2001;293:306-311. 


\section{Figure legends}

Figure 1 : Time course of serum ALT and AST activities following acute $\mathrm{CCl}_{4}$ injury. (A) ALT and (B) AST activities are not significantly different in blood sample of control (Cont) and $\mathrm{CCl}_{4}$-treated WT and $\mathrm{Gas6}^{-/-}$mice at any time point in the experiment (values are means \pm SEM of 8 to 10 mice).

Figure 2 : Time course of hepatocellular necrosis following acute $\mathrm{CCl}_{4}$ injection in WT and Gas6deficient mice. (A) Representative micrographs of paraffin-embedded liver sections from WT and $\mathrm{Gas6}^{-/-} \mathrm{CCl}_{4}$-treated mice (H\&E staining; original magnification X100). A single $\mathrm{CCl}_{4}$ injection induces similar hepatocellular necrosis around central veins (CV) at 48 hour in WT and Gas6-/mice. At 72 hour, the surface of necrotic areas was reduced in WT but not in Gas6 $6^{-/-}$mice. (B) Semi-quantitative analysis of hepatocellular necrosis is performed as described in method section. Necrotic areas are reduced by 50\% in WT mice at 72 hour and in $\mathrm{Gas6}^{-/-}$mice at 96 hour. Values are means \pm SEM of 6 to 10 mice and were identical at 48 hour in both types of mice. ** denotes significantly different values $(\mathrm{P}<0.01)$ between $\mathrm{WT}$ and deficient mice.

Figure 3 : Analysis of hepatocyte proliferation in liver from $\mathrm{CCl}_{4}$-treated mice. (A) Quantitative analysis of PCNA in liver extracts from WT and $\mathrm{Gas6}^{-/-}$mice following $\mathrm{CCl}_{4}$ injection and (B) representative western blots 48 hour after $\mathrm{CCl} 4$ injection in both types of mice. Ratio of PCNA to $\beta$-actin values are expressed as fold over values obtained from WT animals injected with vehicle only (oil). Values are means \pm SEM of 4 to 8 animals. ${ }^{*}$ denotes significant difference $(\mathrm{P}<0.05)$ between WT and deficient mice. $\dagger(\mathrm{P}<0.05)$ and $\dagger \dagger(\mathrm{P}<0.01)$ denote significant difference from control group (Cont). (C) Immunohistochemical detection of PCNA in nuclei of hepatocytes (arrows) on representative paraffin sections (original magnification X200). An increase in PCNApositive nuclei is detected from 48 hour in WT mice and at 72 hour in Gas6-deficient mice. (D) Hepatic IL6 concentration is increased 24 and $48 \mathrm{~h}$ after $\mathrm{CCl}_{4}$ injection and this induction is largely 
prevented in Gas6 ${ }^{-/-}$mice. Values are means of 4 animals and $*(\mathrm{P}<0.05)$ and $* *(\mathrm{P}<0.01)$ denote significant difference between WT and deficient mice.

Figure 4 : Relative changes in hepatic IL6, TNF- $\alpha$, CD14 and MCP-1 mRNA expression after $\mathrm{CCl}_{4}$-induced liver injury in Gas6 ${ }^{-/-}$and WT mice . (A) IL6 mRNA, (B) TNF- $\alpha$ mRNA, (C) CD14 mRNA and (D) MCP-1 mRNA levels analyzed by real-time quantitative RT-PCR at different times after $\mathrm{CCl}_{4}$ injection reveal defective Kupffer cell activation in deficient mice. Values are means \pm SEM of 4 to 8 mice and $* \mathrm{P}<0.05$ and ${ }^{* *} \mathrm{P}<0.01$ denote significant difference between $\mathrm{WT}$ and $\mathrm{Gas6}^{-{ }^{--}}$mice.

Figure 5 : Effect of Gas6 deficiency on monocyte/macrophage recruitment after acute $\mathrm{CCl}_{4}$ liver injury. (A) Immunohistochemical detection of F4/80-positive macrophages (arrows) around the central veins (CV) on liver paraffin sections (original magnification X400). Distribution of macrophages is similar in the liver of WT and $\mathrm{Gas6}^{-/-}$mice at 48 hour and at 72 hour, the accumulation of F4/80-positive cells detected in the centrilobular areas in WT mice is strongly reduced in deficient mice. (B) Immunofluorescent detection of CD68-positive macrophages on liver frozen sections from WT and Gas6 ${ }^{-/}$treated-mice (original magnification X200). At 72 hour, more macrophages are present in necrotic areas of WT mice than in Gas6 $6^{-/-}$mice. (C) Quantitative RTPCR analysis shows that hepatic CD68 mRNA levels are reduced in Gas6 ${ }^{-/-}$mice corroborating the decreased recruitment of CD68-positive macrophages in deficient mice. Values are means \pm SEM of 4 to 8 mice and * $\mathrm{P}<0.05$ denotes significant difference between $\mathrm{WT}$ and deficient mice. (D) Gas6 chemotactic effect on monocytes performed in Boyden’s chambers using 500,000 purified human blood monocytes seeded in the upper wells. Non-specific migration in the lower well in absence of Gas6 (BSA) corresponds to 1.5\% of the cells. Addition of recombinant Gas6 protein in the lower chamber (Gas6) induces a significant increase in cell migration $(* * P<0.001)$ which represents $70 \%$ of the migration induced by recombinant MCP-1 (MCP-1) used as positive control. 
This specific Gas6 chemotactic effect is clearly reduced $\left({ }^{*} \mathrm{P}<0.05\right)$ when recombinant Gas6 was added in upper and lower wells at a same concentration (Gas6/Gas6).

Figure 6 : Effect of Gas6 deficiency on activation of $\mathrm{HSC}$ after $\mathrm{CCl}_{4}$-induced liver injury. Quantitative RT-PCR analysis of hepatic (A) TGF- $\beta$ and (B) $\alpha$-SMA mRNA expression in Gas6 ${ }^{-/-}$ mice is reduced and delayed as compared to WT (* $\mathrm{P}<0.05)$. Values are means \pm SEM of 4 to 8 animals. (C) Immunohistochemical staining of $\alpha$-SMA-positive cells in liver paraffin sections reveals activated HSC/MFB around the central veins (CV) from 72 hour after $\mathrm{CCl}_{4}$ injection in WT animals (original magnification X400) which was largely blunted in Gas6 $^{-/-}$mice (D) Desmin staining at 72 hour is similar in both types of mice . Arrows point desmin-positive cells (original magnification X400).

Figure 7 : Effect of Gas6 deficiency on Axl signal transduction. Densitometric analysis of phosphorylated Axl (A) and NFkB (B) proteins in liver extracts shows a comparable activation of Axl signaling pathway in WT and $\mathrm{Gas6}^{-/-}$mice early after $\mathrm{CCl}_{4}$ injection. Representative (C) and densitometric analysis of western blots (D) reveal a high level of total Axl protein in liver of Gas6 ${ }^{-/-}$ mice. Arbitrary values represent ratio normalized to $\beta$-actin (means \pm SEM of 4 animals). Induction of SOCS1 mRNA quantified by real time PCR (E) is only detected in deficient mice 16 hours after $\mathrm{CCl}_{4}$ injection. Values are means \pm SEM of 4 mice and $* \mathrm{P}<0.05$ and $* * \mathrm{P}<0.01$ denote significant difference between WT and $\mathrm{Gas6}^{-/-}$mice. 
Table 1 : Sequence of primers

\begin{tabular}{|l|l|l|l|l|}
\hline Gene & Forward primer 5’-3’ & Reverse primer 5’-3’ & GI & positions \\
\hline $\boldsymbol{\alpha}$-SMA & GGACGTACAACTGGTATTGTGC & CGGCAGTAGTCACGAAGGAAT & 31982518 & $442 ; 619$ \\
\hline $\mathbf{C D 1 4}$ & GGCTTGTTGCTGTTGCTTC & CAGGGCTCCGAATAGAATCC & 42476052 & $178 ; 481$ \\
\hline $\mathbf{C D 6 8}$ & ACAACTGTCACTCATAACCCTGC & GCCCTCTTTAAGCCCCACTTT & 6753351 & $208 ; 486$ \\
\hline $\mathbf{I L 6}$ & TTCCCTACTTCACAAGTCCGGAGA & ACTCCAGCTTATCTGTTAGGAG & 13624310 & $104 ; 570$ \\
\hline $\mathbf{M C P - 1}$ & GGGCCTGCTGTTCACAGTT & CCAGCCTACTCATTGGGA & 110625629 & $110 ; 231$ \\
\hline SOCS1 & CCGTGGGTCGCGAGAAC & AACTCAGGTAGTCACGGAGTACCG & 87044896 & $713 ; 775$ \\
\hline TGF- $\boldsymbol{\beta}$ & TGACGTCACTGGAGTTGTACGG & GGTTCATGTCATGGATGGTGC & 6755774 & $1461 ; 1630$ \\
\hline $\mathbf{T N F}-\boldsymbol{\alpha}$ & AATGGCCTCCCTCTCATCAGTT & CCACTTGGTGGTTTGCTACGA & 7305584 & $352 ; 460$ \\
\hline
\end{tabular}

Sequence of primers designed for quantitative RT-PCR experiments from GenBank sequences identified by their accession number (GI) and their positions. 
A
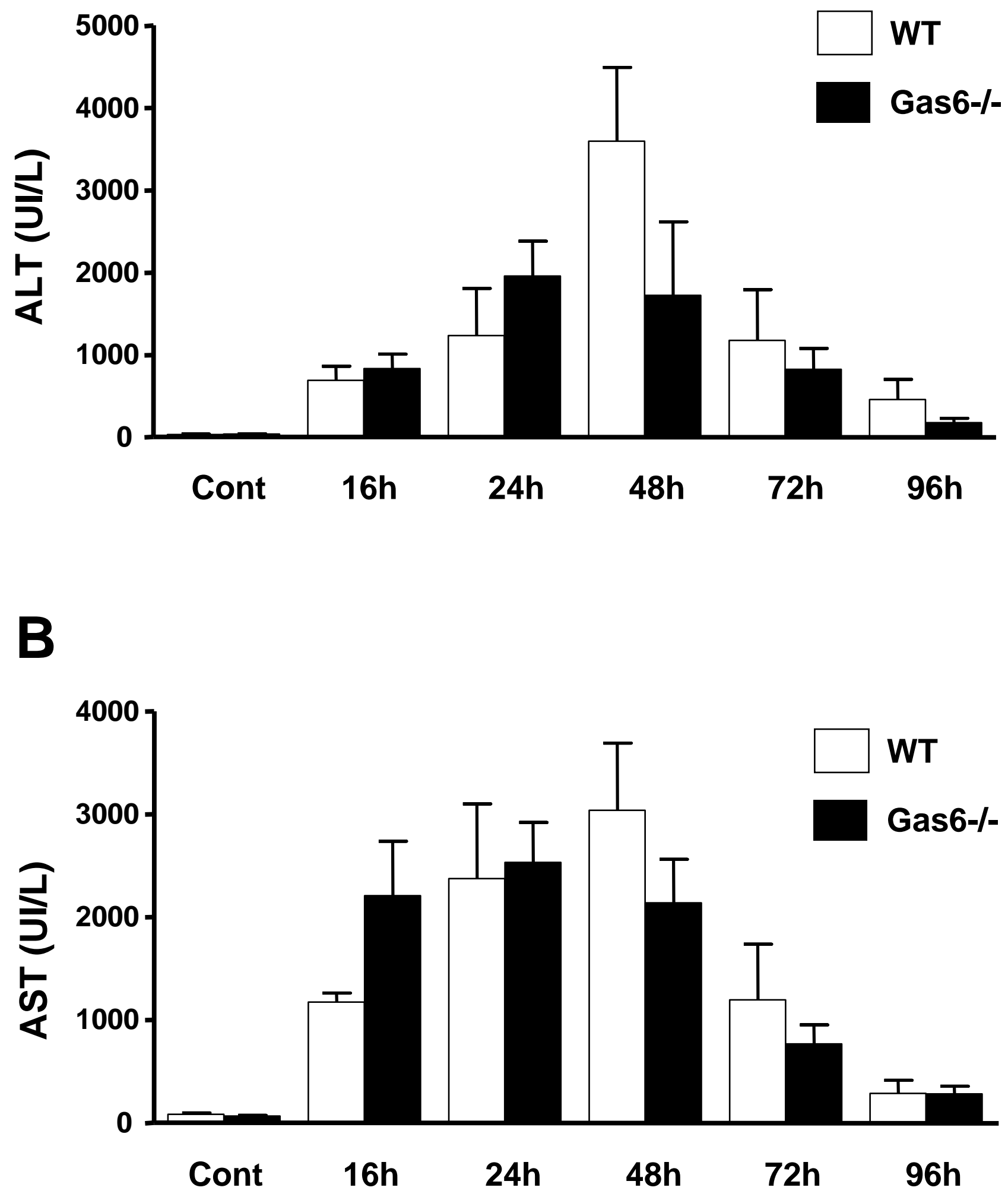

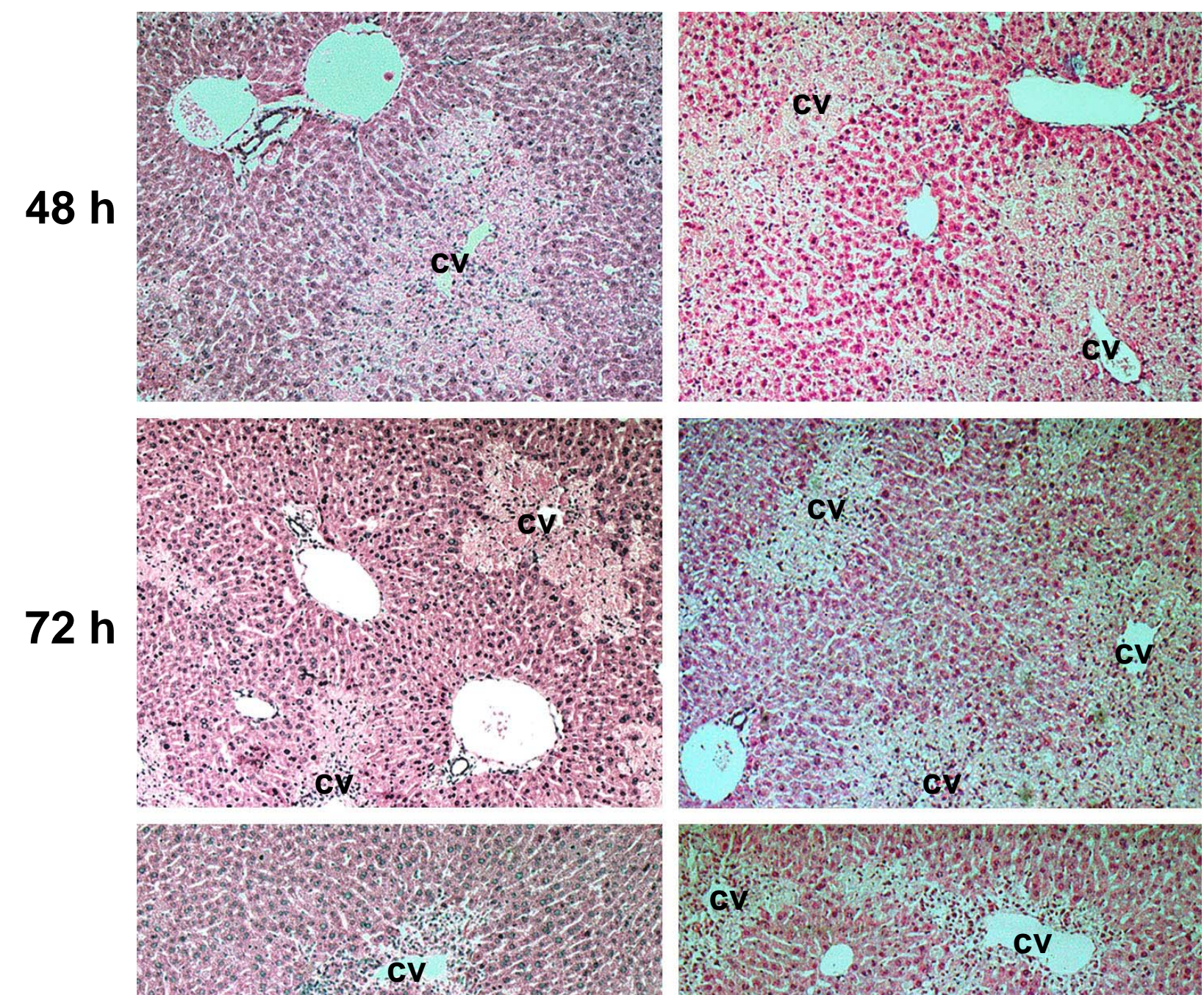

$96 \mathrm{~h}$
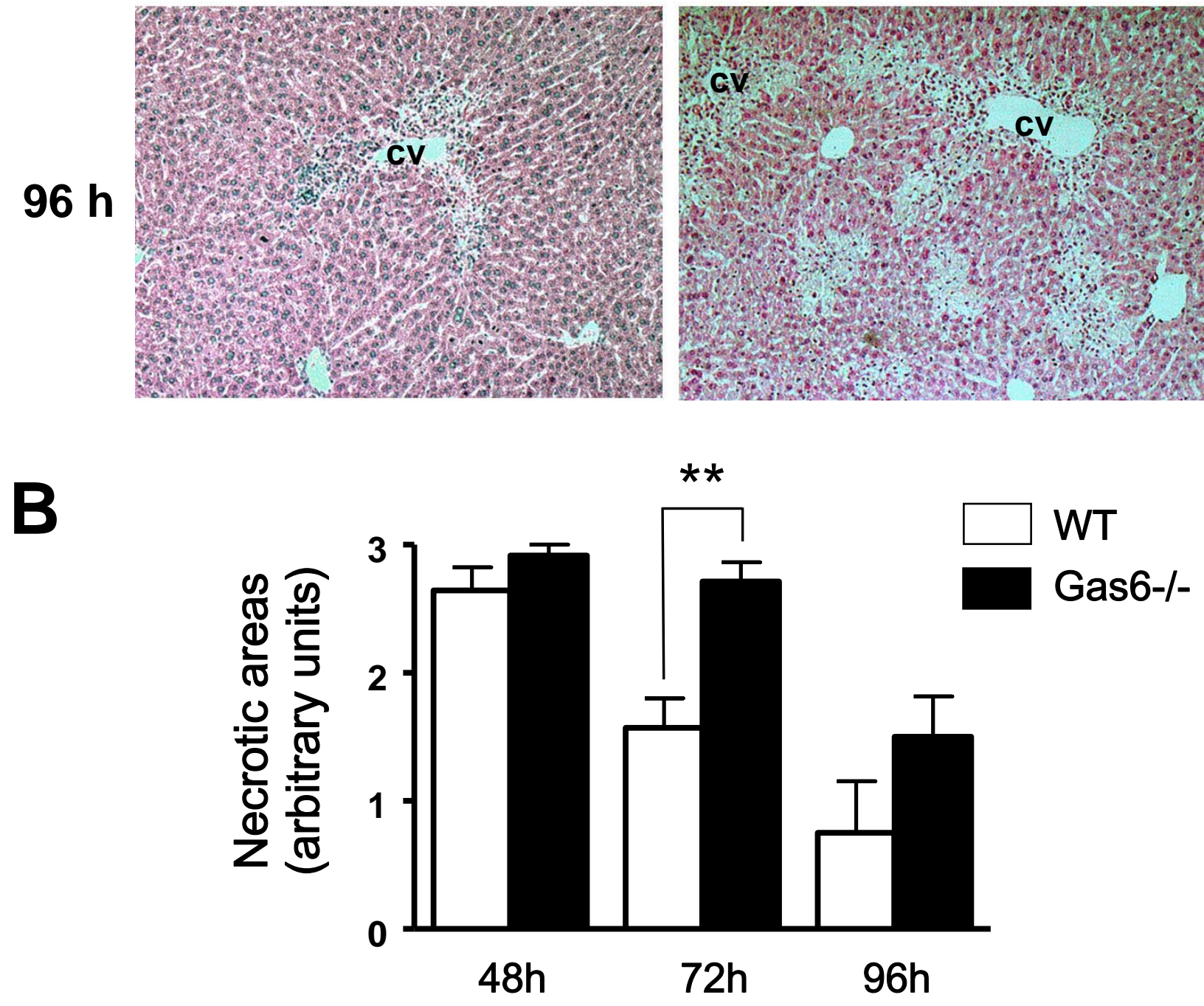


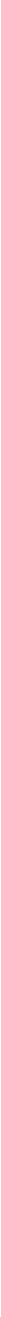



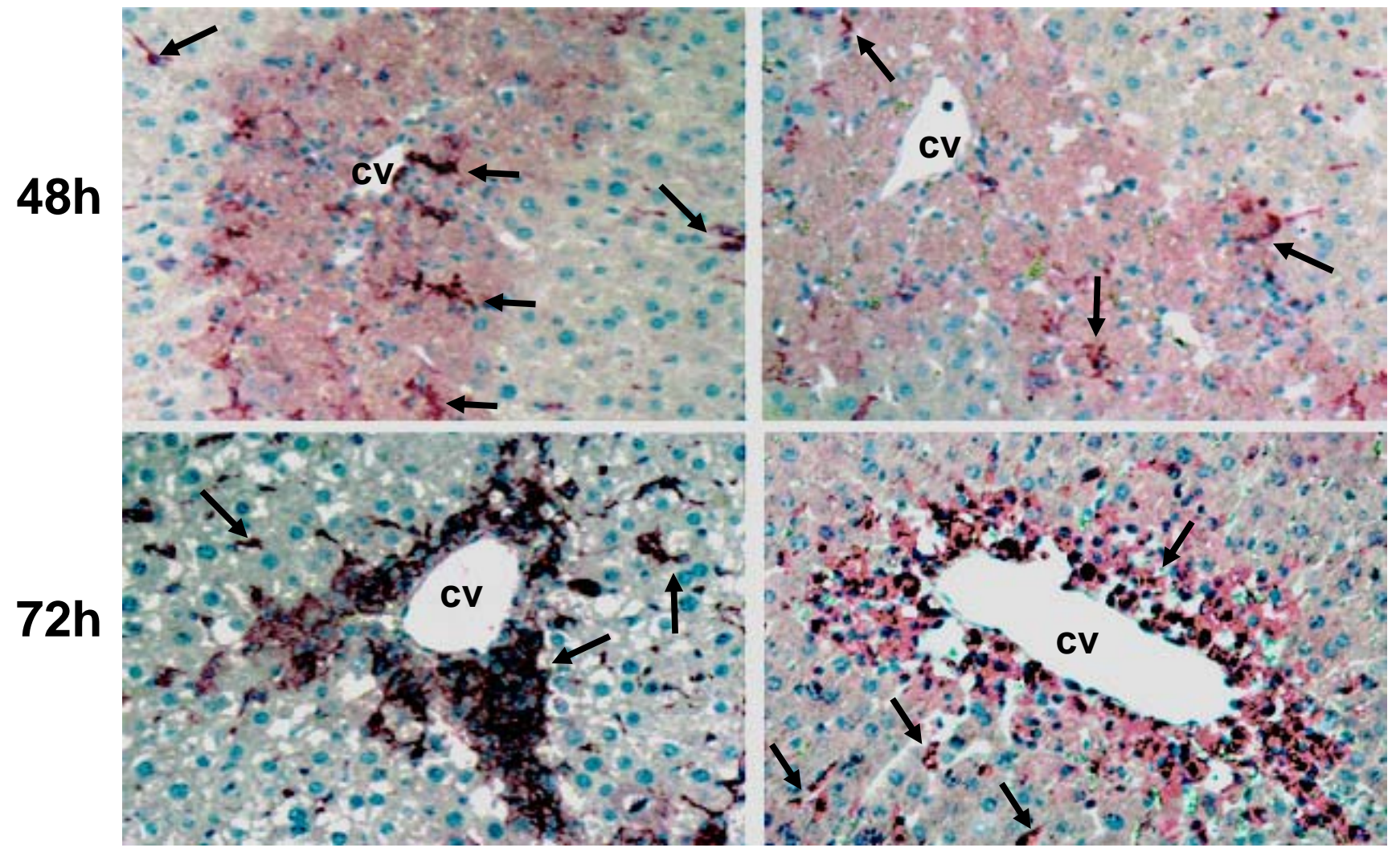

B

\section{WT}

\section{Gas6-I-}
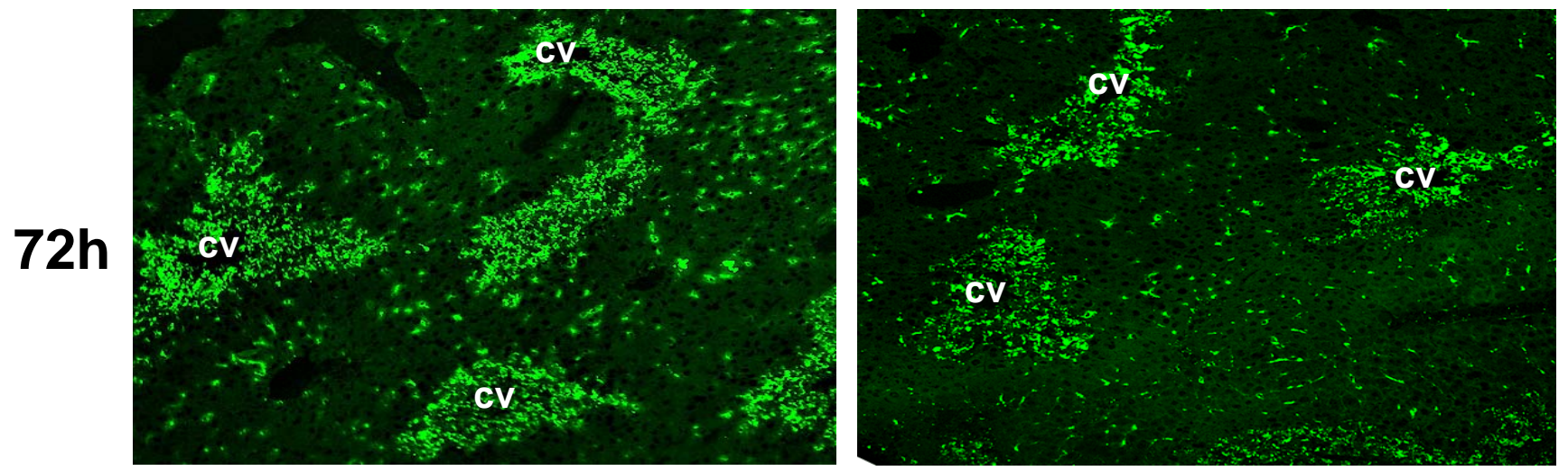

C
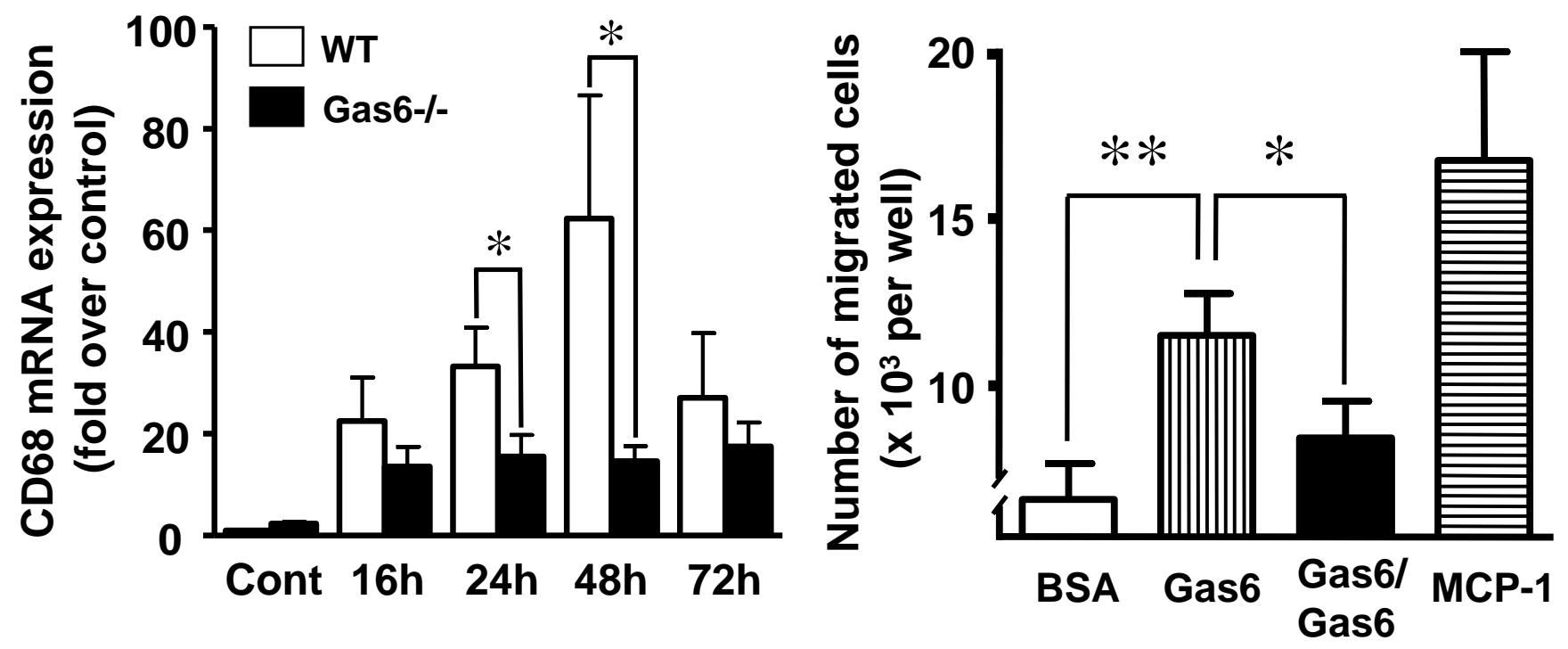

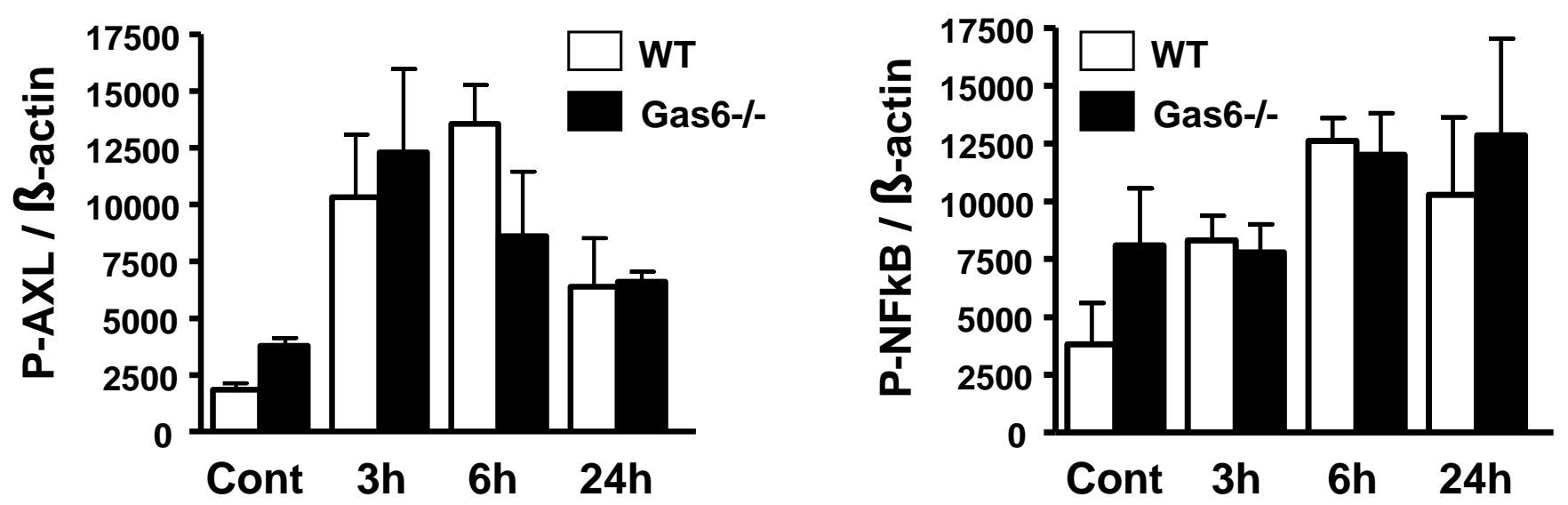

C

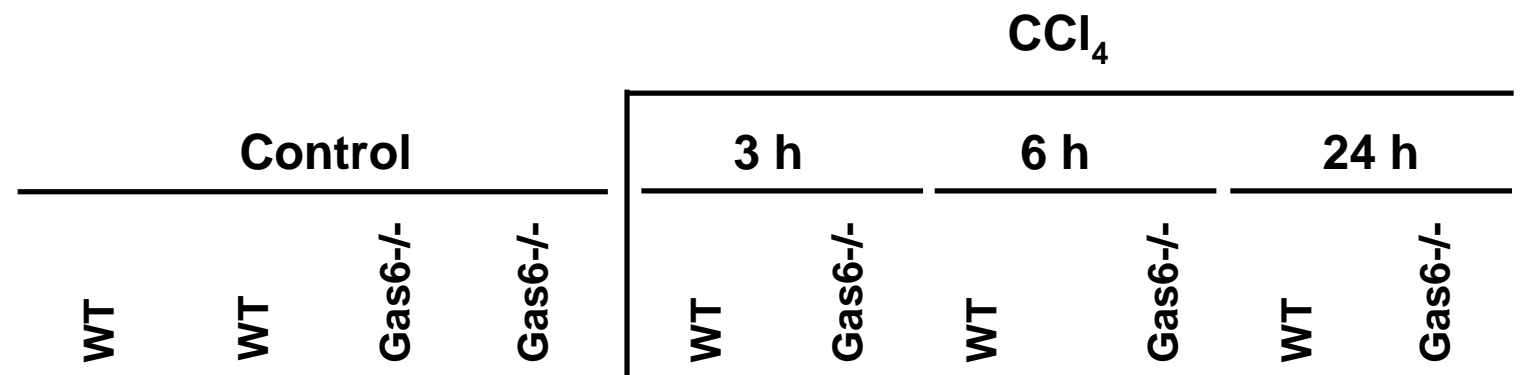

AXL

ß-ACTIN
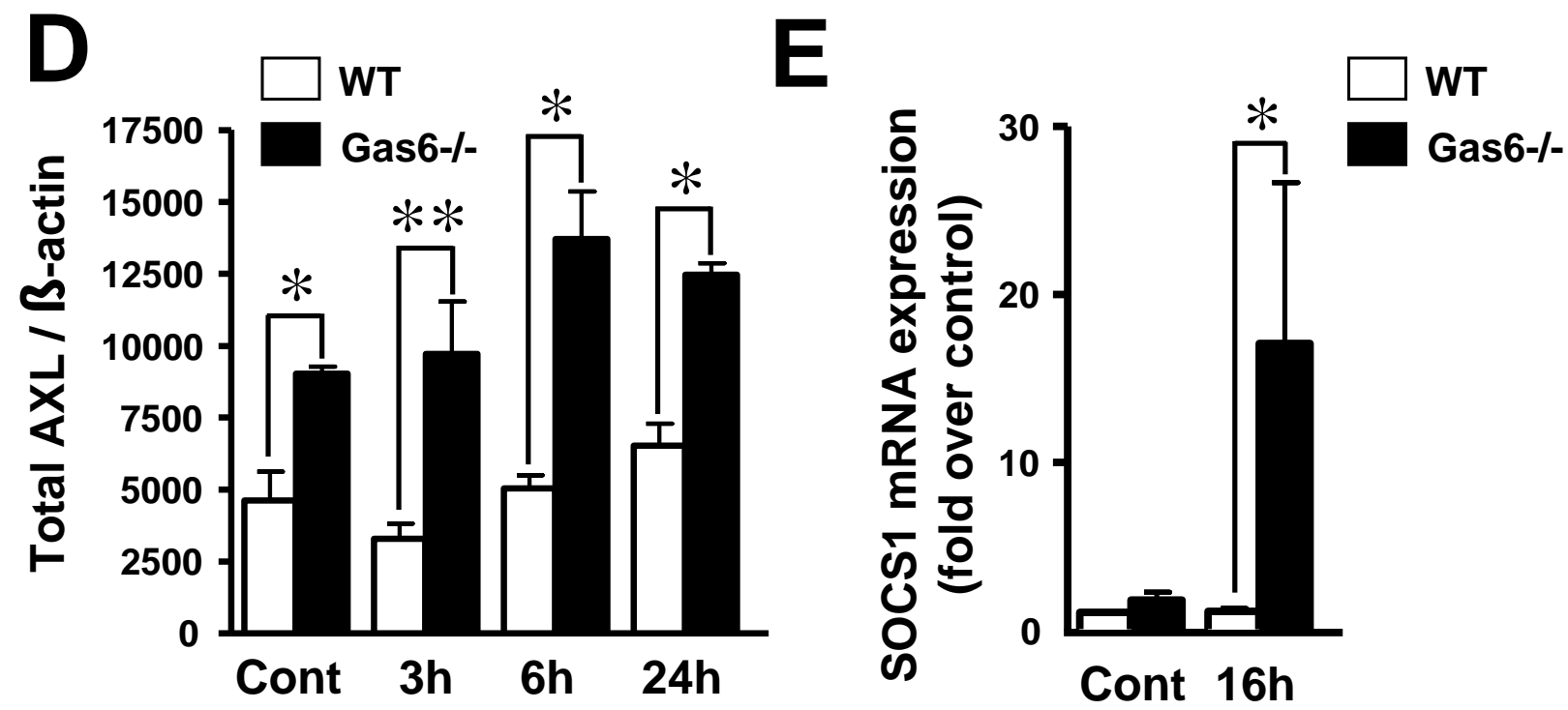